Arq. Bras. Med. Vet. Zootec., v.64, n.6, p.1739-1746, 2012

\title{
Incidência da carne PSE (pale, soft, exsudative) em suínos em razão do tempo de descanso pré-abate e sexo
}

\author{
[Resting time pre-slaughter and sex on the incidence of PSE (pale, soft, exsudative) meat in pigs] \\ J.C. Santiago, F.R. Caldara*, V.M.O. Santos, L.O. Seno, \\ R.G. Garcia, I.C.L.. Almeida Paz \\ Faculdade de Ciências Agrárias - Universidade Federal da Grande Dourados - Dourados, MS
}

\section{RESUMO}

Avaliou-se o efeito do período de descanso pré-abate e do sexo sobre a incidência de carne PSE (pale, soft, exudative) em suínos. Foram realizadas três visitas a abatedouro comercial, nas quais se mensurou o $\mathrm{pH}$ das carcaças $(\mathrm{n}=2128)$ aos 45 minutos após o abate, de lotes compostos por fêmeas, machos castrados cirurgicamente e machos imunocastrados e de lotes mistos (fêmeas e machos castrados cirurgicamente), submetidos a período de descanso que variou de duas a 16 horas. Carcaças com $\mathrm{pH}_{45} \leq 5,8$ foram classificadas como PSE, e com $\mathrm{pH}_{45}>5,8$ como normais. Em função do número de animais avaliados dentro de cada categoria, estimou-se a frequência de carne PSE. A incidência total de carne PSE foi de $10,1 \%$, sendo maior nos lotes de animais imunocastrados (13,5\%) quando comparados aos lotes de fêmeas $(8,6 \%)$ ou de machos castrados cirurgicamente $(8,5 \%)$. Períodos de descanso menores que seis horas e acima de 14 horas aumentaram a incidência de carne PSE. Período de descanso entre seis e oito horas minimizaram a ocorrência de carnes PSE.

Palavras-chave: estresse, imunocastração, manejo pré-abate, $\mathrm{pH}_{45}$, suíno

\begin{abstract}
Were evaluated the effect of lairage pre-slaughter and sex on the incidence of PSE (pale, soft and exudative) meat in pigs. There were three visits to a commercial slaughterhouse, in which the pH of carcasses $(n=2128)$ was measured at 45 minutes after slaughter of lots consisting exclusively of females, males castrated surgically, males immunologically castrated and mixed lots (females and castrated surgically) underwent a resting time, and time between the shipment and slaughter ranged from two to 16 hours. Carcasses with $p H 45 \leq 5.8$ were classified as PSE and with $p H 45>5.8$ as normal. Depending on the number of animals evaluated in each category we estimated the frequency of PSE. The overall incidence of PSE meat was 10.1\%, higher in lots of animals immunocastrated (13.5\%) compared to lots of females $(8.6 \%)$ or castrated males (8.5\%). Resting time of less than six hours and up to 14 hours increased the incidence of PSE meat. Resting time between six and eight hours minimized the occurrence of PSE meat.
\end{abstract}

Keywords: immunocastration, $\mathrm{pH}_{45}$, pre-slaughter handling, stress, swine

\section{INTRODUÇÃO}

O investimento na produção de suínos (genética, nutrição, sanidade e sistemas de produção) foi crescente nos últimos anos e teve como objetivo a obtenção de um animal competitivo. No entanto, o novo modelo de animal trouxe

Recebido em 27 de maio de 2012

Aceito em 10 de outubro de 2012

* Autor para correspondência (corresponding author)

E-mail: fabianacaldara@ufgd.edu.br desafios, principalmente nos aspectos de manejo pré-abate (Silveira, 2001), tornando os animais mais sensíveis ao estresse. Quando submetidos a condições estressantes durante o manejo préabate, os suínos apresentam modificações bioquímicas musculares consideráveis (Costa et $a l .$, 2002) que podem interferir de forma decisiva na qualidade de sua carne. Fatores como tempo de transporte da granja ao frigorífico, manejo no 
período pré-abate e tempo de descanso dos animais antes do abate (Andrade et al., 1992; Van der Wal et al., 1997) podem influenciar de forma significativa a incidência de carne PSE (pale, soft, $d$ exudative).

O período de descanso no frigorífico é uma importante prática de manejo, que tem sido utilizada para possibilitar a recuperação dos animais do estresse físico e emocional ocorrido no transporte. Para tanto, é usual deixar os animais em repouso nas baias do frigorífico de uma a três horas, tempo considerado para a recuperação das reservas de glicogênio, baseado em avaliações de $\mathrm{pH}$, cor e perda de água da carne (Warris et al., 1998). Contudo, o período de descanso ótimo depende da logística do estabelecimento e da intensidade do estresse a que os suínos foram submetidos durante o manejo pré-abate (Santos et al., 1997; Giespert et al., 2000).

Sabe-se que suínos machos inteiros apresentam comportamento agressivo e atividade sexual, resultando em danos nas carcaças, que aumentam progressivamente à medida que o suíno atinge os estágios mais avançados da puberdade (Thun et al., 2006), além do problema relacionado ao odor na carcaça, sendo, deste modo, a castração de machos destinados ao abate uma prática comum e obrigatória no Brasil. A castração imunológica com anti-GnRH é um procedimento que pode substituir a castração cirúrgica de suínos machos, sendo eficaz em reduzir as concentrações de androstenona e escatol, responsáveis pelo odor na carcaça, garantindo ainda bom desempenho e a qualidade de carcaça dos animais (Font i Furnols et al., 2008). A sua aplicação, porém, deve ser estudada com cautela, de forma que possa ser analisada a viabilidade econômica na implantação dessa técnica, além da questão de bem-estar animal, pois a castração cirúrgica causa desconforto momentâneo, enquanto a imunocastração permite que os animais apresentem comportamento sexual e acabem agredindo-se uns aos outros, quando em baias coletivas. Este fato pode ocasionar estresse aos animais nas pocilgas de espera, nos momentos que antecedem o abate, aumentando a incidência de carcaças PSE.

O objetivo do trabalho foi verificar a incidência de carne PSE em abatedouro comercial e sua relação com o tempo de descanso pré-abate e o sexo dos animais.

\section{MATERIAL E MÉTODOS}

Foram realizadas três avaliações, entre os meses de maio e dezembro de 2009, em um abatedouro comercial, situado no município de Dourados, MS, com capacidade de abate de 2300 cabeças/dia, representando, aproximadamente, $50 \%$ do abate do estado do Mato Grosso do Sul.

Os dados meteorológicos referentes às datas das avaliações no abatedouro foram obtidos da Estação Meteorológica da Universidade Federal da Grande Dourados. Utilizando-se os valores médios diários de temperatura e umidade relativa do ar, foram calculadas as temperaturas de bulbo seco ( $\mathrm{t} b s$ ) e bulbo úmido ( $\mathrm{t} b u$ ) do ar, por meio do programa Psicrom ${ }^{\circledR}$ (Roriz, 2003), e, posteriormente, os índices de temperatura e umidade (ITU), empregando-se a equação 1 (Thom, 1958):

$\mathrm{ITU}=0,72(\mathrm{t} b s+\mathrm{t} b u)+40,6$.

O manejo pré-abate foi padronizado para todos os animais, com exceção do tempo de descanso. O tempo de jejum efetivo anterior ao transporte foi de, aproximadamente, seis horas. Os animais mais pesados de cada baia eram selecionados para embarque, e a condução era realizada com auxílio de tábuas de manejo, havendo, dessa forma, a mistura de lotes a partir desse momento. Os animais foram molhados e embarcados por meio de rampas elevadiças até a carroceria do caminhão. A densidade de transporte dos suínos ao abatedouro foi padronizada na faixa de 250 a $280 \mathrm{~kg}$ de peso vivo por $\mathrm{m}^{2}$. Após desembarque, os animais foram encaminhados à pocilga de descanso, sendo alojados em densidade de $0,65 \mathrm{~m}^{2} /$ animal. Depois de cumprido o período de descanso, foram guiados ao abate utilizando-se tábuas de manejo até a seringa e, só então, foi usado o bastão elétrico para que o animal entrasse na esteira rolante.

Os suínos, da mesma linhagem genética, selecionada para alta deposição de carne magra na carcaça, foram abatidos com peso vivo médio de $115 \mathrm{~kg}$, seguindo protocolo de abate convencional após insensibilização por eletronarcose, separadamente, de acordo com o sexo, sendo lotes formados por fêmeas, por machos imunocastrados, machos castrados cirurgicamente e lotes mistos de fêmeas e machos castrados cirurgicamente. 
Para avaliação da incidência de carne PSE, mensurou-se o pH de 2128 carcaças, aos 45 minutos $\left(\mathrm{pH}_{45}\right)$ após o abate, por método direto, utilizando-se um peagâmetro portátil acoplado a uma sonda com ponta fina de penetração, inserida no centro do músculo Longissimus dorsi, da meia carcaça esquerda, entre a $12^{\mathrm{a}}$ e a $13^{\mathrm{a}}$ vértebra torácica. Carcaças com $\mathrm{pH}_{45} \leq 5,8$ foram classificadas como PSE, e aquelas com $\mathrm{pH}_{45}>5,8$ como normais (Velazco, 2001).

Para avaliação dos efeitos do período de descanso sobre a incidência de carne PSE, foi utilizado o tempo total de descanso na pocilga do abatedouro, dividido em classes em virtude da duração: duas a quatro; quatro a seis; seis a oito; oito a $10 ; 10$ a $12 ; 12$ a 14; 14 a 16 horas.

A incidência total de carne PSE foi obtida utilizando-se a quantidade de animais positivos para PSE $\left(\mathrm{pH}_{45} \geq 5,8\right)$ em relação ao número total de animais avaliados, expressa em porcentagem. A incidência de PSE em razão do sexo e do manejo pré-abate foi mensurada pelo número de animais diagnosticados como PSE em relação ao número de animais de cada sexo e em cada tempo de descanso avaliados.

A análise da estatística foi realizada com auxílio do programa Statistical Analysis System (Statistical..., 2001). Os valores de $\mathrm{pH}_{45}$ foram avaliados quanto às pressuposições do modelo (normalidade e homocedasticidade). Não atendendo às pressuposições, foram realizadas análises não paramétricas, utilizando-se o teste de Kruskal-Wallis. O teste de qui-quadrado foi utilizado para comparação da frequência de carnes PSE entre os diferentes sexos e tempos de descanso no abatedouro.

\section{RESULTADOS E DISCUSSÃO}

$\mathrm{O}$ pH aos 45 minutos após o abate apresentou ampla variação com maior frequência na faixa de 6,0 a 6,2, havendo, entretanto, quantidade significativa de carcaças com $\mathrm{pH}$ acima e abaixo desses valores.

A incidência total de carne PSE foi de 10,1\%. Esse valor é mais baixo que os observados por outros pesquisadores brasileiros, que obtiveram percentuais de 22,8\% (Maganhini et al., 2007) e 46,4\% (Culau et al., 2002) na região Sul do país. Tal redução pode ser explicada, em parte, pelo fato de a maioria das empresas atuantes no mercado de genética suinícola disponibilizar atualmente no mercado muitas linhagens livres do gene halotano, bem como pelo constante aprimoramento nas técnicas de manejo pré-abate, com maior conscientização em todos os segmentos da cadeia sobre os princípios de bemestar animal e suas consequências na qualidade da carne.

O percentual de carcaças PSE foi semelhante para os lotes formados por fêmeas $(8,6 \%)$ e machos castrados (8,5\%). Entretanto, esse percentual foi elevado quando essas duas categorias foram misturadas no mesmo lote $(11,3 \%)$, embora não diferentes estatisticamente. A incidência de carcaças PSE também foi mais elevada nos lotes de machos imunocastrados $(13,5 \%)$, sendo, aproximadamente, cinco pontos percentuais maior quando comparada à de machos castrados e de fêmeas (Fig. 1).

Ao avaliarem a incidência de carne PSE em planta de abate comercial, Castrillón et al. (2007) observaram que o sexo relacionou-se de forma significativa com o $\mathrm{pH}_{45}$. Carcaças de suínos machos apresentaram maiores valores de $\mathrm{pH}_{45} \mathrm{e}$ incidência de $24,7 \%$ de carne PSE, enquanto as fêmeas apresentaram 25,7\% de carcaças PSE.

Em contrapartida, Bridi et al. (2006) verificaram que as fêmeas não apresentaram carcaças com carne PSE, mas, em machos castrados, a frequência foi de 25\%. Segundo Ellis (1998), carcaças mais pesadas apresentam menores valores de $\mathrm{pH}$ inicial e final, o que resulta em maior incidência de carne PSE. Em mesma idade, machos castrados cirurgicamente possuem maior peso de abate que fêmeas, fato que pode ocasionar a maior incidência de PSE nesses animais. Entretanto, no presente estudo, o abate dos animais foi padronizado pelo peso e não pela idade, sendo todos os animais abatidos com a mesma faixa de peso, o que poderia explicar o fato de a incidência de PSE não ter diferido entre fêmeas e machos castrados cirurgicamente. 


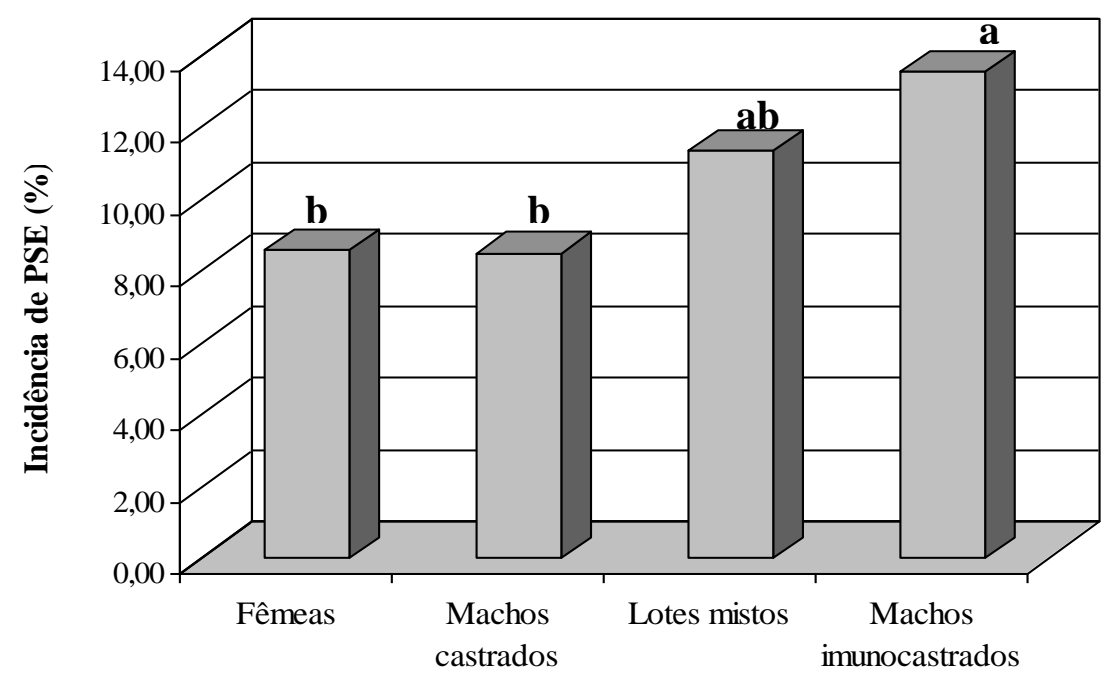

Sexo

Figura 1. Incidência (\%) de carcaças PSE em lotes de suínos machos castrados, imunocastrados, fêmeas e em lotes mistos (fêmeas e machos castrados cirurgicamente).

Pesquisas não demonstraram diferenças entre fêmeas, machos castrados cirurgicamente e imunocastrados quanto a parâmetros qualitativos da carne suína, como $\mathrm{pH}$ aos 45 minutos post mortem, pH final, coloração e capacidade de retenção de água (Jeong et al., 2008; Pauly et al., 2009; Gispert et al., 2010).

A castração cirúrgica de leitões machos para evitar odor sexual é cada vez mais criticada por razões de bem-estar dos animais (Prunier et al., 2006). As consequências negativas da castração têm sido consideradas devido ao estresse e à dor durante e logo após a castração cirúrgica. No entanto, a castração também pode propiciar benefícios ao bem-estar animal com a possibilidade de reduzir as interações agressivas e sexuais entre eles (Velarde et al., 2007). Ambas as alterações comportamentais podem ser interpretadas como benéficas para o bem-estar dos animais e devem ser levadas em consideração na análise custo-benefício da castração cirúrgica, bem como as estratégias alternativas para lidar com o problema de odor de macho inteiro.

Pesquisas têm demonstrado que o nível plasmático de testosterona se mantém em torno de sete a 25 vezes menor em suínos imunocastrados em comparação a machos inteiros (Dunshea et al., 2001). Entretanto, a imunização não bloqueia completamente a produção de hormônios esteroides e, embora reduza os comportamentos agressivos (Zamaratskaia et al., 2008), permitiria a estes animais expressarem, mesmo que em menor proporção, comportamentos masculinos. Este fato poderia explicar a maior incidência de carne PSE observada no presente experimento, fruto de maiores interações agressivas entre animais, considerando-se ainda o fato de os animais de diferentes lotes, não familiarizados, terem sido misturados durante o transporte e pocilga de descanso.

Houve efeito $(\mathrm{P}<0,05)$ da data de avaliação sobre a incidência de carne PSE. A maior incidência foi observada na segunda avaliação, cuja caracterização do ambiente pode ser observada na Tab. 1. Embora o ITU nesta avaliação se encontrasse dentro da faixa de conforto térmico para suínos nesta faixa de peso $(61<$ ITU $\leq 65)$ (Sales et al., 2006), a maior incidência pode estar mais relacionada ao sexo do que às condições ambientais, uma vez que nesta avaliação só foram abatidos machos imunocastrados e lotes mistos, os quais apresentaram a maior frequência de PSE na avaliação global.

O tempo de descanso pré-abate influenciou o $\mathrm{pH}$ das carcaças aos 45 minutos após o abate, bem como a incidência de carne PSE (Fig. 2). 
Tabela 1. Temperatura de bulbo seco (TBS), temperatura de bulbo úmido (TBU) e índice de temperatura e umidade (ITU) referentes às datas de avaliação no abatedouro

\begin{tabular}{ccccc}
\hline Avaliação & TBS & TBU & ITU & \%PSE \\
\hline 1 & 22,10 & 18,22 & 69,63 & $8,41 \mathrm{~b}$ \\
2 & 15,30 & 13,50 & 61,34 & $12,07 \mathrm{a}$ \\
3 & 23,70 & 16,08 & 69,24 & $10,62 \mathrm{ab}$ \\
\hline
\end{tabular}

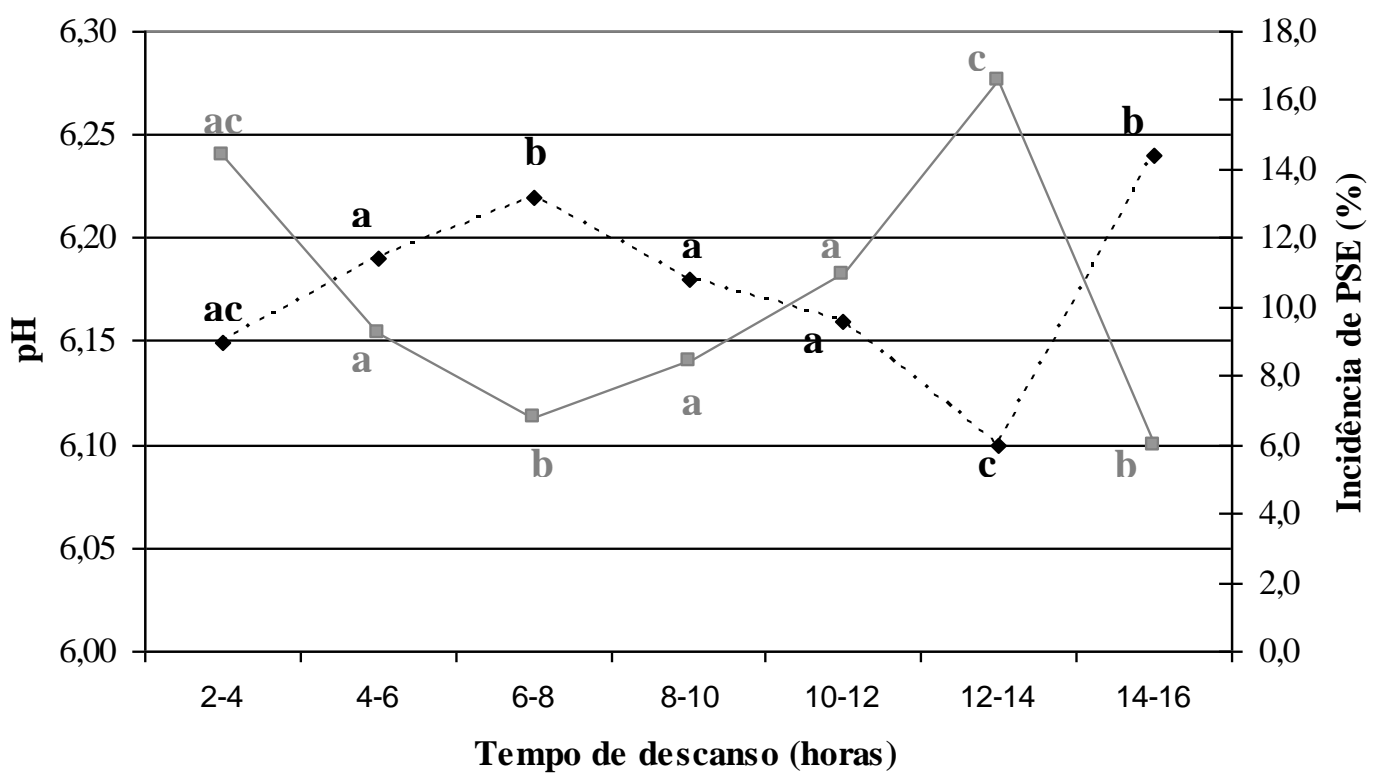

$$
\cdots \cdot \mathrm{PH} \longrightarrow \% \mathrm{PSE}
$$

Figura 2. Médias de pH aos 45 minutos e incidência de carne PSE em razão do tempo de descanso de suínos no abatedouro $(\mathrm{n}=2128)$.

Houve aumento dos valores de $\mathrm{pH}_{45}$, com concomitante redução na incidência de carcaças PSE, quando este se situou entre seis e oito horas. Períodos de descanso inferiores a seis horas e superiores a oito horas elevaram a incidência de carne PSE, sendo a maior incidência observada para os animais cujo período de descanso variou entre 12 e 14 horas. Período de descanso superior a 14 horas aumentou significativamente os valores de $\mathrm{pH}_{45}$, com redução na incidência de PSE.

No manejo pré-abate, os suínos são submetidos a estresse devido ao embarque, transporte e desembarque no frigorífico, promovendo elevação nos níveis sanguíneos e musculares de ácido lático, elevação da temperatura corporal e aceleração do metabolismo. Estes animais precisam eliminar o excesso de ácido lático acumulado nos músculos e restabelecer o seu equilíbrio homeostático, o qual somente pode ser alcançado com a adoção de períodos de descanso adequados (Dalla Costa et al., 2005).

O descanso pré-abate tem demonstrado benefícios na redução da incidência de carne PSE, entretanto, dependendo de sua duração, pode aumentar a quantidade de lesões na pele e o aparecimento de carne dura, seca e escura (DFD) (Warriss et al., 1998). Com base nessas pesquisas, os autores sugerem que duas a três horas de descanso são suficientes para permitir que os animais se recuperem do estresse prévio à sua chegada ao abatedouro, sem aumentar os problemas da privação prolongada de alimento, depleção de glicogênio muscular e escoriações na pele.

Para Grandin (1994), o período de descanso préabate ótimo para limitar o aparecimento de carne PSE é de duas a quatro horas, enquanto para outros autores este período deve ser de duas a seis horas (Denaburski et al., 2001). Entretanto, 
o tempo de descanso pode variar amplamente de uma a mais de 24 horas, segundo características particulares.

No presente trabalho, contudo, observou-se que o tempo mais adequado para recuperação dos animais e consequente redução da incidência de carne PSE situou-se entre seis e oito horas. Esta diferença pode estar relacionada às condições climáticas, uma vez que, em condições de clima tropical, o estresse do manejo e transporte dos animais é muito mais severo quando comparado a condições de clima mais ameno.

Avaliando a diferença entre dois tempos de descanso na pocilga do frigorífico (30 minutos e duas a três horas), Santos et al. (1997) obtiveram pH 24 horas post mortem de 5,59 e 5,65, respectivamente, demonstrando que períodos muito curtos podem reduzir o $\mathrm{pH}$ da carne e, consequentemente, aumentar a incidência de carne PSE. Em contrapartida, Köhler e Freitas (2005), ao avaliarem períodos de descanso menores que 30 minutos a nove horas, não observaram diferença no $\mathrm{pH}$ e na temperatura do músculo Longissimus dorsi aos 45 minutos post mortem.

Após a mistura de suínos não familiarizados na pocilga de descanso, rapidamente se começa a estabelecer uma hierarquia de dominância. A hierarquia é estabelecida em média dentro de duas horas e só a partir daí os animais começam a descansar (Grandin, 1994). Desse modo, o abate de suínos nas primeiras horas de descanso, durante período crítico de comportamento agressivo, no qual os animais encontram-se submetidos a estresse físico e fisiológico, irá resultar em aumento da atividade metabólica, redução do pH intramuscular (Enfalt et al., 1993) e temperatura corporal elevada, aumentando a incidência de carne PSE. Van der Wal et al. (1997), ao avaliarem as causas da variação na qualidade de carne, relataram que brigas durante o período de descanso, nas baias de espera, iniciaram-se aproximadamente 25 minutos depois da chegada dos suínos no frigorífico e duraram cerca de duas horas. Este fato poderia explicar a maior incidência de PSE observada no presente estudo para o grupo de animais submetidos ao período de descanso de duas a quatro horas.

Após quatro horas, os suínos em descanso começam a acordar e voltam a apresentar comportamento agressivo que pode afetar a qualidade da carne (Grandin, 1994). Considerando-se que, no presente estudo, os animais foram submetidos à mistura de lotes não familiares durante o transporte e período de descanso, o aumento da incidência de carcaças PSE após oito horas de descanso pode estar relacionado ao aumento da agressão entre animais submetidos a período de espera muito prolongado. Köhler e Freitas (2005) verificaram que a redução do tempo de descanso reduziu o número de escoriações na pele, hematomas e fraturas provenientes de agressões entre animais.

Considerando-se o jejum alimentar pré-embarque em torno de seis horas e o tempo de transporte médio de uma a duas horas, os animais cujo período de descanso foi maior que 14 horas foram submetidos a jejum total de pelo menos 21 horas. Este período prolongado de jejum configura quadro que compromete os princípios de bem-estar animal. Associado ao estresse da mistura entre lotes durante o transporte e descanso, pode ter resultado na redução das reservas de glicogênio muscular, prejudicando a acidificação da carne, o que explica a redução da incidência de PSE neste grupo de animais.

\section{CONCLUSÕES}

A incidência de carne PSE em abatedouro comercial é de aproximadamente $10 \%$, não diferindo entre fêmeas e machos castrados cirurgicamente. Entretanto, a incidência desta anomalia foi superior em machos imunocastrados. O período de descanso pré-abate influencia de forma significativa a incidência de carne PSE, sendo seis a oito horas o período mais adequado para minimizar o problema. 


\section{REFERÊNCIAS}

ANDRADE JÚNIOR, R.; NICOLAIEWSKY, S.; OURIQUE, J.M.R. et al. Análise de alguns fatores determinantes da qualidadeda carne suína. I. Efeito da distância Granja-Frigorífico, tempo de descanso, sexo e peso vivo. In: CONGRESSO BRASILEIRO DE MEDICINA VETERINÁRIA, 22., 1992, Curitiba. Anais... Curitiba,1992. p.216.

BRIDI, A.M.; OLIVEIRA, A.R.; FONSECA, N.A.N. et al. Efeito do genótipo halotano, da ractopamina e do sexo do animal na qualidade da carne suína. Rev. Bras. Zootec., v.35, p.20272033, 2006.

CASTRILLÓN， W.E.; FERNÁNDEZ， J.A.; RESTREPO, L.F. Variables asociadas con la presentación de carne PSE (Pálida, Suave, Exudativa) en canales de cerdo. Rev. Col. Cienc. Pec., v.20, p.327-338, 2007.

COSTA, L.M.; LO FIEGO, D.P.; DALL'OLIO, $\mathrm{S}$. et al. Combined effects of pre-slaughter treatments and lairage time on carcass and meat quality in pigs of different halothane genotype. Meat Sci., v.61, p.41-47, 2002.

CULAU, P.O.V.; LÓPEZ, J.; RUBENSAM, J.M. et al. Influência do gene halotano sobre a qualidade da carne. Rev. Bras. Zootec., v.31, p.954-961, 2002.

DALLA COSTA, O.A.; BERTOL, T.M.; LUDKE, J.V. et al. Efeito de manejo pré-abate e da posição do box dentro da carroceria sobre o perfil hormonal de suínos. Comunicado técnico 406. Embrapa - CNPSA, Concórdia, SC, 2005.

DENABURSKI, J.; SÁIZ, C.F.; BAX, T. Causas más importantes y sistemas de prevención de casos de carne porcina defectuosa tipo PSE. Anaporc, v.217, p.35-43, 2001.

DUNSHEA, F.R.; COLANTONI, C.; HOWARD, K. et al. Vaccination of boars with a GnRH vaccine (Improvac) eliminates boar taint and increases growth performance. J. Anim. Sci., v.79, p.2524$2535,2001$.

ELLIS, M. Genetic and nutritional influence on pork quality. In: SIMPÓSIO SOBRE RENDIMENTO E QUALIDADE DA CARNE SUÍNA, 1., 1998, Concórdia. Anais... Concórdia: EMBRAPA, 1998. p.25-54.
ENFALT, A.C.; LUNDSTRÖM, K.; ENGSTRAND, U. Early postmortem $\mathrm{pH}$ decrease in porcine $\mathrm{M}$. Longissimus dorsi of PSE, normal and DFD quality. Meat Sci., v.34, p.131-143, 1993.

FONT I FURNOLS, M.; GISPERT, M.; GUERRERO, L. et al. Consumers' sensory acceptability of pork from immunocastrated male pigs. Meat Sci., v.80, p.1013-1018, 2008.

GIESPERT, M.; FAUCITANO, L.; OLIVER, M.A. et al. A survey of pre-slaughter conditions, halothane gene frequency, and carcass and meat quality in five Spanish pig commercial abattoirs. Meat Sci., v.55, p.97-106, 2000.

GISPERT, M.; OLIVER, M.A.; VELARDE, A. et al. Carcass and meat quality characteristics of immunocastrated male, surgically castrated male, entire male and female pigs. Meat Sci., v.85, p.664-670, 2010.

GRANDIN, T. Methods to reduce PSE and Blood splash. Proc. Allen D. Leman Swine Confr. University of MN, v.21, p.206-209, 1994.

JEONG, J.Y.; CHOI, J.H.; HAN, D.J. et al. The effects of immunocastration on meat quality and sensory properties of pork loins. In: INTERNATIONAL PIG VETERINARY SOCIETY CONGRESS, 20., 2008, Durban. Proceedings... Durban , 2008. CD Rom

KÖHLER, R.G.; FREITAS, R.J.S. Qualidade da Carne Suína após dois tempos de Descanso no Frigorífico. Arch. Vet. Sci., v.10, p.89-94, 2005.

MAGANHINI, M.B.; MARIANO, B.; SOARES, A.L. et al. Carnes PSE (Pale, Soft, Exudative) e DFD (Dark, Firm, Dry) em lombo suíno numa linha de abate industrial. Cienc. Tecnol. Aliment., v.27, supl., p.69-72, 2007.

PAULY, C.; SPRING, P.; O'DOHERTY, J.V. et al. Growthperformance, carcass characteristics and meat quality of group penned surgically castrated, immunocastrated (Improvac) and entire males pigs andindividually penned entire male pigs. Animal, v.3, p.1057-1066, 2009.

PRUNIER, A.; BONNEAU, M.; VON BORELL, E.H. et al. A review of the welfare consequences of surgical castration in piglets and evaluation of non-surgical methods. Anim. Welfare, v.15, p.277-289, 2006. 
RORIZ, M. Psicrom $1.0 \quad-\quad$ Relações Psicométricas. Universidade Federal de São Carlos, Departamento de Engenharia Civil. Programa de Pós-Graduação em Construção Civil. São Carlos, 2003.

SALES, G.T.; FIALHO, E.T.; YANAGI JUNIOR, T. et al. A influência do ambiente térmico no desempenho reprodutivo de fêmeas suínas. In: CONGRESSO BRASILEIRO DE ENGENHARIA AGRÍCOLA, 35., 2006. João Pessoa. Anais... João Pessoa: , 2006. CD ROM.

SANTOS, C.; ALMEIDA, J.N.; MATIAS, E.C. et al. Influence of lairage environmental conditions and resting time on meat quality in pigs. Meat Sci., v.45, p.253-262, 1997.

SILVEIRA, F.T.E. Carne sem estresse. Suinocultura Industrial. Porto Feliz: CD Rom, 2001. p.31-32.

THOM, E.C. Cooling degree - day air conditioning, heating and ventilating. Transact. ASAE, v.55, p.65-72, 1958.

THUN, R.; GAJEWSKI, Z.; JANETT, F.F. Castration in male pigs: techniques and animal welfare issues. J. Physiol. Pharmacol., v.57, Suppl.8, p.189-194, 2006.
VAN DER WAL, P.G.; ENGEL, B.; HULSEGGE, B. Causes for variation in pork quality. Meat Sci., v.46, p.319-327, 1997.

VELARDE, A.; GISPERT, M.; OLIVER, M.A. et al. The effect of immunocastration on the behaviour of pigs. In: INTERNATIONAL CONGRESS OF THE INTERNATIONAL SOCIETY FOR APPLIED ETHOLOGY, 41., 2007, Merida. Proceedings ... Merida: 2007.

VELAZCO, J. Prevención de PSE en carne de cerdo. Carne Tec., v.8, p.28-34, 2001.

WARRISS, P.D.; BROWN, S.N.; EDWARDS, J.E. et al. Effect of lairage time on levels of stress and meat quality in pigs. Anim. Sci., v.66, p.255-261, 1998.

ZAMARATSKAIA, G.; RYDHMER, L.; ANDERSSON, H.K. et al. Long-term effect of vaccination against gonadotropin-releasing hormone, using Improvac ${ }^{\mathrm{TM}}$, on hormonal profile and behaviour of male pigs. Anim. Reprod. Sci., v.108, p.37-48, 2008. 